\title{
O CONTEXTO DE FUNDAÇÃO DA ESCOLA DE EDUCAÇÃO FÍSICA E DESPORTOS DO PARANÁ: EDUCANDO CORPOS PARA A VIDA URBANA
}

\author{
MS. MARCELO MORAES E SILVA \\ Mestre em Educação UFPR \\ Doutorando em Educação UNICAMP \\ (Campinas - São Paulo - Brasil) \\ e-mail: moraes_marc@yahoo.com.br \\ DR. ANDRÉ MENDES CAPRARO \\ Doutor em História UFPR \\ Professor do Departamento de Educação Física UFPR \\ Professor dos Programas de Pós-Graduação em História e Educação Física UFPR \\ (Curitiba - Paraná- Brasil) \\ e-mail: andrecapraro@onda.com.br
}

\begin{abstract}
RESUMO
O presente artigo objetiva analisar o contexto sócio-político que favoreceu a fundação de uma instituição que visava especificamente formar profissionais na área de Educação Física, a Escola de Educação Física e Desportos do Paraná. Fundada em Curitiba no ano de 1942, a Escola foi fruto de um cenário político amplo, no qual o Estado, permeado por ideais higiênicos/ eugênicos, passa a se preocupar mais com a educação formal. Como reflexo, novas condutas fisicas e morais foram incorporadas por meio das práticas presentes nos currículos escolares. A Escola de Educação Física e Desportos do Paraná, mesmo com as suas singularidades, fez parte ativamente deste processo.
\end{abstract}

PALAVRAS-CHAVE: Escola de Educação Física e Desportos do Paraná; Educação Física; sistema educacional; Curitiba. 


\section{CONSIDERAÇÕES INICIAIS}

Apesar da preocupação com a Educação Física e os exercícios físicos já estarem presentes no Brasil desde o século XIX uma formação profissional especifica só começou a surgir nos princípios do século $X X$. Os primeiros a desejarem a formação profissional foram os militares e os passos iniciais em direção a esta a formação se deram a partir de 1902, no Batalhão de Caçadores, no Quartel da Luz na cidade de São Paulo, que oferecia uma formação em ginástica e esgrima. Em 1909 essa escola foi transformada e passa a ser chamada de Escola de Educação Física da Força Policial (MELO, 1996).

É também oriundo desse período o surgimento das primeiras preocupações do Estado em relação a formação dos profissionais em Educação Física. Já em 1905 , o deputado amazonense Jorge de Morais apresenta um projeto junto ao Congresso Nacional, propondo a criação de duas Escolas de Educação Física, uma civil e outra militar. Conforme lembra Melo (1996), apesar de aprovado, esse projeto não foi concretizado. Contudo, os militares, agora apoiados por médicos e educadores, deram continuidade ao esforço de organizar e sistematizar uma formação profissional em Educação Física. Um exemplo marcante foi a fundação, em 1922, do Centro Militar de Educação Física, localizado junto a Escola de Sargentos de Infantaria da Vila Militar do Rio de Janeiro, embrião inicial da Escola de Educação Física do Exército (EsEFEx), criada em 1933.

As iniciativas civis também se intensificaram em solo nacional, tanto que na década de 1930, os governos dos estados de São Paulo e Espírito Santo criaram os seus respectivos Departamentos de Educação Física. Estes, posteriormente, abririam Escolas de Educação Física. Apesar dessas iniciativas, foi somente no final dos anos 1930, durante a gestão presidencial de Getúlio Vargas, que a formação universitária em Educação Física passou a ser alvo de uma política estatal mais ampla (MELO, 1996).

O primeiro passo para a efetivação desse projeto ocorreu em 1937, quando o governo federal criou por meio do Ministério da Educação e Saúde (MES), a Divisão de Educação Física (DEF), importante órgão na propagação da Educação Física no território brasileiro. Esse Departamento seria o primeiro aparelho governamental em esfera federal responsável em sistematizar e regulamentar todo o processo de formação superior. O segundo passo realizado pelo governo Getúlio Vargas, foi à promulgação do Decreto-Lei 1212 de 1939, que cria a Escola Nacional de Educação Física, vinculada à antiga Universidade do Brasil.

Tais empreendimentos federais mudaram profundamente a formação, pois, por iniciativa desse decreto e pelas ações do DEF a instituição se tornava modelo para as outras existentes no país (em São Paulo e no Espírito Santo), bem como para 
as futuras escolas que seriam criadas no Rio Grande do Sul (1941), Paraná (1942), Pernambuco (1947), São Carlos (1950), Minas Gerais (1952) e Bauru (1953).

No estado do Paraná, mais precisamente em sua capital, a preocupação com a formação superior em Educação Física também se mostrou presente. E é tentando compreender o porquê da sociedade curitibana sentir a necessidade de uma Escola de Educação Física que o presente artigo se justifica. Foi nessa Curitiba ainda em remodelação que surgiu uma das primeiras instituições de formação superior em Educação Física do Brasil. A Escola de Educação Física e Desportos do Paraná foi uma instituição de ensino superior criada na mesma época em que Curitiba buscava por meio de práticas políticas, econômicas e culturais mostrar para o restante do país a imagem de uma urbe moderna, cosmopolita e civilizada. Sendo assim, as seguintes perguntas ganham grande pertinência: como foi possível que saberes especializados se institucionalizassem para educar corpos de uma dada população urbana? Em que medida a ascensão de um modo de vida urbano foi decisivo para a criação de um Instituto Superior de Educação Física em Curitiba? Para responder tais questões torna-se necessário fazer uma breve incursão sobre a "invenção" de Curitiba, cidade-modelo.

\section{CURITIBA: INVENTANDO A URBE}

Até meados dos anos oitocentos, Curitiba sequer era a cidade mais desenvolvida do Estado, até esse momento tratava-se tão somente de uma vila que servia de passagem para os tropeiros e que sobrevivia de um pequeno comércio. Com a emancipação política de São Paulo, em I853, a antiga 5a . Comarca se tornou uma Província independente. Com isso Curitiba apesar de sua péssima condição estrutural foi escolhida para ser a capital da nova unidade do governo imperial.

Como uma cidade sem estrutura material foi elevada a capital de uma Província? Entende-se que apesar da falta de condições ela foi escolhida por algumas características. Entre elas pode-se destacar sua excelente localização geográfica, clima agradável (mais parecido com o europeu) e principalmente pelo fator eugênico, pois a população local era basicamente de imigrantes europeus, ou seja, não existia uma predominância de indivíduos de ascendência indígena e africana, como havia nas regiões dos Campos Gerais e no Litoral (AVÉ-LALLEMENT, 1995).

Além desses aspectos era um lócus ideal para evitar o principal choque político entre as elites econômicas da Província: os habitantes do litoral (exportadores de erva-mate) e dos Campos Gerais (fazendeiros e/ou tropeiros). Pereira (1996) salienta que a partir da elevação da cidade à capital estes dois grupos se estabeleceram na região urbana de Curitiba. $\bigcirc$ autor lembra que essa disputa também 
ocorreu no plano cultural, já que os proprietários de terra preferiam os padrões luso-brasileiros e a burguesia ervateira preferia um ecletismo europeu. Entretanto, em outras situações, tais grupos agiram de forma conjunta. Afinal, ambos estavam impregnados de valores cosmopolitas e modernizantes que os levaram a rejeitar os costumes populares, tentando enraizar valores e regras mais urbanas, civilizadas e higiênicas no corpo da população!

Baseados no ideário civilizador, os governantes paranaenses efetuaram várias medidas no ultimo quartel dos oitocentos. A elite dirigente trouxe para Curitiba diversas comunidades de imigrantes europeus. Na época da gestão de Adolpho Lamenha Lins (| 875-1877), foi instalado ao redor da cidade um cinturão de colônias de estrangeiros. A conformação proporcionada por esses agrupamentos foi marcante para o futuro urbano da cidade. Curitiba pretendia ser a capital modelo para o restante do Brasil no quesito que articulava urbanização e imigração europeia. Diferentemente das experiências anteriores, quando as colônias ficavam distantes dos núcleos urbanos, estas se localizavam em volta da capital num denominado cinturão de colônias.

O desenvolvimento econômico proporcionado pelo mate possibilitou uma maior integração dos imigrantes em se tratando do contexto social e cultural de Curitiba. Esse grupo de indivíduos de origem europeia contribuiu significativamente para a modernização da cidade, pois percebeu vantagens na demanda econômica gerada a partir da sua chegada, principalmente em relação aos seus respectivos hábitos de consumo (alimentares, têxteis, residenciais e serviços em geral). Foram eles, por exemplo, que contribuíram na circulação de diversos discursos especializados sobre o corpo, entre eles os relacionados às práticas corporais, pois em suas terras natais os exercícios físicos, principalmente a ginástica, já eram praticados em larga escala. Foi a partir disso que surgiram algumas entidades imigrantes que difundiam as práticas formais de ginástica e de esportes na cidade².

I. A título de exemplo fica a proibição que as autoridades impuseram à população paranaense de praticar diversos tipos de divertimento. Entre eles podem-se destacar as práticas de fandango, entrudo, batuques e brigas de galo.

2. Já existia na cidade, na segunda metade do século XIX, uma série de associações e clubes imigrantes que incentivam as práticas de ginásticas e esportivas. Destaque para os clubes alemães Gesangverein Germânia ( I 869), que mais tarde se funde com outros já existentes como o Gesangverein Concórdia, Verein Deutcher Saegerbund, o Gesangverein Frohsinn e o Deutcher Turverein (primeira sociedade ginástica de Curitiba) e Sociedade de Tiro ao Alvo, sob nome de Clube Concórdia. Entre os alemães se destacam ainda o Teuto Brasilianischer Turn Verein zu Curitiba ( 1890 ), que em português significa: Clube de Ginástica Teuto Brasileiro de Curitiba, que posteriormente foi chamado de Clube Duque de Caxias e o Coritiba Foot Ball Club, clube de futebol fundado em 1909, por iniciativa de alguns membros da Teuto Brasilianischer Turn Verein zu Curitiba. (FUGMANN, 2008). Existiam também 
Nos estudos de Trindade (1996) e Boni (1998), as autoras argumentam que o discurso civilizatório efetuado no século XIX se materializou claramente no espaço urbano de Curitiba nas primeiras décadas do século $X X$. Tanto que as autoridades municipais desse período iniciaram um amplo processo de reestruturação urbana. As ruas se abriam e foram pavimentadas, surgiram novas edificações, arranha-céus e o próprio traçado da cidade se tornava mais compacto. Por sua vez, o governo aprimorou seus serviços na área de educação e saúde, higienizou o centro urbano com a construção de galerias pluviais, expansão da rede de água e esgotos, irrigação e limpeza pública. Também implementou os planos de arborização, calçamento, bonde elétrico, normatização na circulação de veículos, iluminação pública, construção de praças, parques, teatros e cinemas e, inclusive, o de criação de uma guarda civil e algumas prisões ${ }^{3}$.

Esta onda civilizatória trouxe ao Estado do Paraná um crescimento populacional considerável. De 126.722 habitantes em 1872, passou para 327.136 em 1900. Só em Curitiba a população era em 1905 de 53.928 e em 1920 esse número passou a ser de 78.986 habitantes. Com um agrupamento maior de indivíduos na cidade novos "padrões de comportamento" foram criados para um melhor convívio urbano e algumas retóricas discursivas para a educação dos corpos foram acionadas. Constata Pereira (1996), que foi a partir do início do discurso civilizatório, ainda no século XIX, que a elite começou a se preocupar com os hábitos populares. E essas ações estavam sempre baseadas numa crença na ciência. Dentre as diversas estratégias estavam os processos de escolarização, pois tais processos começaram a ser cobrados no sentido de conformar na população os novos hábitos "urbanos".

\section{EDUCANDO CORPOS EM CURITIBA}

A escolarização para as massas no imaginário republicano brasileiro foi o signo da instauração de uma "nova" ordem, uma arma para alcançar a "Ordem e o Progresso". Nesse período tinha como intento formar um "novo" tipo de indivíduo - forte, adestrado e intrépido. A instituição escolar surge como lugar apropriado para educar os corpos, controlando seus gestos, modificando suas condutas e disseminando novos modos de vida e comportamento.

agremiações esportivas nas colônias polonesas, italianas e ucranianas na cidade, bem como as da elite dirigente como o Clube Curitibano (TRINDADE, 1996).

3. Para atender às novas necessidades da população houve um aprimoramento dos ambientes públicos, que se tornaram importantes áreas de lazer (bandas de música, cafés, praças, salões de dança, cinemas, teatros, clubes esportivos e etc.) (BONI, 1998; TRINDADE, 1996). 
Trindade e Andreazza (200 I), afirmam que vários intelectuais paranaenses defendiam essa mesma mudança para as escolas locais. Segundo as autoras, a cidade de Curitiba passou de três grupos escolares em 1893 para dez em 1916. Além desse avanço na instrução primária, ocorreu um processo de investimento em outros ramos de ensino, como o profissional e o superior com a criação de algumas instituições: a Escola de Belas Artes e Indústria do Paraná (1 886), Conservatório de Belas Artes (1894), a Escola de Aprendizes e Artífices (1909), Escola Profissional Feminina (1917) e a Universidade do Paraná (1912).

Contudo, foi somente na década de 1920, que o Estado do Paraná, no governo de Caetano Munhoz da Rocha, intensificou uma ampla campanha para o melhoramento do seu sistema educacional. As medidas reformistas foram capitaneadas por Lysimaco Ferreira da Costa, então diretor de ensino do estado e César Pietro Martinez, educador vindo do Estado de São Paulo, para exercer o cargo de Inspetor Geral de Ensino. Tais intelectuais desejavam mudar hábitos, regenerar costumes e modificar caracteres, ou seja, formar corpos instrumentalizados, higienizados, imbuídos de racionalidade e engajados num ideal de nacionalidade. Foi nesse momento que ocorreu um amplo processo de assimilação do imigrante. Apesar de suas virtudes laboriosas e higiênicas, era necessário inserir nesses indivíduos a noção de nação, pois os imigrantes eram uma ameaça para a unidade nacional.

Com as medidas reformistas ocorreu um amplo processo de reestruturação na instrução pública paranaense. Lysimaco Ferreira da Costa realizou em 1922 a separação entre a Escola Normal e o Ginásio Paranaense. O desmembramento foi uma manobra política dos católicos liderados por Lysimaco Ferreira da Costa e César Prieto Martinez para enfraquecer os anticlericais liderados por Dario Vellozo e Sebastião Paraná, que disputavam a hegemonia com os católicos pelo controle dos processos de escolarização no estado.

As mudanças realizadas no governo de Caetano Munhoz da Rocha estavam em sintonia com os ideais difundidos no contexto nacional por Anísio Teixeira, Fernando de Azevedo e Lourenço Filho. Tanto que o próprio Lysimaco Ferreira da Costa, conjuntamente com os intelectuais de maior destaque nacional, foi um dos fundadores, em 1924, da Associação Brasileira de Educação (ABE).

Para efetivar a imagem de estado moderno, também nos assuntos concernentes a educação, o governo paranaense organizou na cidade de Curitiba o I Congresso de Ensino Primário e Normal em 1926 e a I Conferência Nacional de Educação em 1927. Em ambos os eventos as teses defendidas pelos diversos participantes giravam em torno principalmente das idéias de laboriosidade, ordem, higiene e civismo 
(unidade nacional). Dessa forma, estavam postas as condições para a entrada nos currículos escolares de determinados discursos sobre o corpo, principalmente a higiene $e^{4}$ e os exercícios físicos ${ }^{5}$.

Esses discursos sobre o corpo se efetivaram no estado, tanto que a higiene e a Educação Física, bem como a Inspeção Médico-Escolar, foram inseridas e passaram a ser mais valorizadas nos currículos do ensino primário e secundários paranaenses. Tais disciplinas escolares estavam ligadas às novas normas sociais, que exigiam indivíduos possuidores de valores e comportamentos mais adequados à vida urbana. No meio de tantas discórdias os grupos católicos e os anticlericais convergiam em alguns quesitos, no bojo desse processo encontrava-se à inserção dos discursos especializados sobre o corpo nos currículos escolares.

Ao refletir acerca da presença das disciplinas de Higiene e de Educação Física na nova configuração curricular brasileira e paranaense, fica impossível não relevar a grande preocupação com os aspectos relacionados à moral médica-sanitária nos processos de escolarização ${ }^{6}$. A preocupação com a higiene não visava somente conformar nos corpos hábitos de vida mais saudáveis. Procurava enraizar na população um modo de vida urbano marcado por um forte ideário médico-higienista e nacionalista.

Essa relação entre a Educação Física e Higiene se mostrou presente num relatório apresentado pelo Inspetor Geral de Ensino, César Pietro Martinez:

A educação physica, considerada como base da educação moral e intellectual, deve merecer os mesmos cuidados da educação do espírito, isto é, desenvolver harmonica e progressivamente a robustez e a destreza do corpo, de accordo com as condições anatomicas e

4. A Higiene e a Eugenia foram muito debatidas nos eventos paranaenses, tanto que na / Conferência Nacional de Educação os principais eugenistas brasileiros, como Belisário Pena e Renato Kelh estiveram presentes. Soares (2008) lembra que nesse período a Higiene passa a ser associada à educação, pois passa a ser um remédio adequado para "curar" as doenças do povo e do país. União que, segundo a autora, levaria ao surgimento de um "novo" Brasil.

5. Soares (2008) lembra que no Brasil foi a partir dos anos de 1920, que passam a circular com mais ênfase os discursos em defesa da Educação Física. Visto que foi nesse período que começa um intenso debate sobre a higienização da população. São criadas nesse período a Liga Brasileira de Higiene Mental, a Sociedade Brasileira de Higiene, o Instituto Brasileiro de Eugenia, a Sociedade Eugência de São Paulo e a Associação Brasileira de Educação. Linhales (2006) indica que apesar da prevalência da ginástica nos projetos da Associação Brasileira de Educação, no que se refere às práticas corporais. Existia desde a primeira conferência em 1927, realizada na cidade de Curitiba, um investimento nas práticas esportivas, como importante atributo na educação do corpo, pois elas seriam primordiais para a energização do caráter das crianças. Contudo, a autora lembra que tal fato não se deu de forma pacifica, pois havia um grande confronto entre uma "mentalidade esportiva" contra uma "mentalidade médico-pedagógico", que preferia a utilização dos métodos ginásticos.

6. Soares (2008) salienta que a disciplina Educação Física foi sistematizada como um prolongamento pedagógico da Higiene, que por sua vez se construiu numa dependência direta do discurso oriundo do saber médico. 
physiológicas do educando. Si ha uma Sciencia da Educação, ella abrange a aptidão physica e estabelece leis tão rigorosas, postulados os mais exigentes, para que esta aptidão realize verdadeira obra de aperfeiçoamento. (...) ○ exame médico, portanto, é a base de todo o programa de gymnastica individual, pois nem se compreende que tratando-se da vida de um ser cujo organismo se desenvolve por idades, se possa por de lado a higiene e a medicina. (...) É necessário, portanto, entregar essa parte importantíssima da educação a quem disso apenas cuide (...) na nossa capital, a empresa não é dif́́cil, pois dispõe o Estado de magníficos elementos na sua briosa e disciplinada Força Militar, capazes de darem ao ensino da gymnástica uma organização magnífica (MARTINEZ, I921, p. 58-59).

\section{A FALTA DE FORMAÇÃO DE PROFESSORES DE EDUCAÇÃO FÍSICA}

Para que tais questões se efetivassem era necessário que tivesse mão de obra especializada e disponível para exercer tal função, pois diferentemente do relato do Inspetor Geral, não existiam, em nenhuma localidade do país, militares em número suficiente para a realização de tal empreitada. Tanto que no I Congresso Brasileiro de Eugenia, III Conferência Nacional de Educação e no V Congresso Brasileiro de Higiene, todos realizados no ano de 1929, já havia registros sobre o intento de criação de Institutos de Educação Física, destinados a formação de instrutores técnicos (LINHALES, 2006).

Apesar da preocupação com a Educação Física já circular nas legislações do Paraná desde 1882, tal prática sistematizada não tinha se materializado de maneira eficaz. Uma das razões era a carência de mão de obra especializada para exercer essa função nos espaços escolares. O primeiro passo para solucionar tais questões foi a criação, no ano de 1931, da Inspetoria de Educação Física do Estado do Paraná, que teve como primeiro inspetor Francisco Mateus Albizú, fundador da Escola de Educação Física e Desportos do Paraná.

Nesse sentido, alguns intelectuais curitibanos atuantes nos anos de 1930 já trabalhavam em prol da Educação Física, vários inclusive propunham a criação de uma Escola Superior de Educação Física na cidade de Curitiba. O desejo de implementar uma instituição com tal função estava em sintonia com o contexto nacional, pois conforme argumenta Linhales (2006), desde o VII Congresso Nacional de Educação, realizado em 1935, no Rio de Janeiro, que teve como tema central a Educação Física, discutiu-se muito sobre a criação das Escolas Superiores de Educação Física. Tanto que o Major-médico Máximo Pinheiro de Lima, já fazia circular retóricas discursivas a favor da Educação Física na cidade de Curitiba. Em matéria do jornal "O Estado", intitulada "O aperfeiçoamento da raça", de 21/02/1937, o médico advoga em prol da criação de uma instituição de ensino superior em Educação Física na capital paranaense. 
O ESTADO, notificou a realização de um curso rápido de ginástica para professores levado a efeito durante as férias e ontem, 20, terminado.

As aulas teóricas estiveram a cargo do Dr. Máximo Pinheiro de Lima, proficiente clínico que se especializou em Educação Física e as práticas, do tenente Aristhenis Sarmento.

Findo dos trabalhos daquela organização técnica, ofereceu-se nos ensejo de uma troca de impressões com aquele abalizado clínico que nos encareceu a importância da iniciativa do diretor de Educação, Dr. Gaspar Velloso, concorrendo para sua efetivação.

- Domingo - disse-nos o Dr. Pinheiro de Lima - teremos ensejo de entregar um certificado de aprovação a sessenta professores paranaenses, vindos de vários pontos, frequentaram com assiduidade as lições de Educação Física. Não se cogita, propriamente, de um curso que demandava mais tempo. Foram apenas aulas dentro de um programa sintético e relativas a biometria, fisiologia ligada a educação. Fizemos sabatinas e provas finais, dentro de certo rigor, que reclamava, é lógico, muito esforço do magistério. E este, por sua dedicação, por sua inteligência, correspondeu plenamente as exigências. A Educação Física, pode disso ficar certo, para quantos trabalham nas fileiras de ensino e da medicina deixou de ser aquela maneira de cansar as crianças nas vésperas das festas. É algo muito sério com a finalidade de embelezar o corpo, dando-lhe desenvolvimento e equilíbrio. Para tanto, vivemos, dentro de recursos modestos, lutando. E vai se conseguindo algum resultado. Há na Assembleia um projeto criando uma escola de Educação Física, mediante a modesta dotação de 50 contos. Se lográssemos sua passagem, poderíamos instituir esse curso ainda esse ano. E é o que esperamos do patriotismo dos Srs. Congressistas. Trata-se de uma quantia pequena. Mas em quantos benefícios ela reverteria para a melhoria da raça! São Paulo criou duas escolas de Educação Física. A da capital disporá de 3 mil contos para a sua expansão e funcionamento. A de Campinas 2.000 contos para o mesmo objetivo. Nós daremos os primeiros passos com apenas 50 contos para a instalação de um curso de um ano, donde sairão mestres preparados para a criação de um curso de um ano, donde sairão mestres preparados para a incrementação da ginástica racional em todo o Estado. O que já fizemos é relativamente muito. E o que pretendemos fazer nos dará ensejo para mostrarmos a conveniência e o valor desse ramo da educação (PINHEIRO DE LIMA, 1937, p. I).

repertório discursivo acionado pelo médico estava em sintonia com os circulantes no contexto nacional, pois versava principalmente sobre as questões da utilidade pedagógica da Educação Física. No entanto, a efetivação da instituição demorou alguns anos para se concretizar. A Escola de Educação Física e Desportos do Paraná foi fundada somente no ano de 1941.

\section{A ESCOLA DE EDUCAÇÃO FÍSICA E DESPORTOS DO PARANÁ}

Era uma instituição de caráter privado e de propriedade de seu fundador, o então Inspetor de Educação Física do Estado, o professor Francisco Mateus Albizú. Após sua criação a instituição obteve autorização para o seu funcionamento 
junto ao Governo Federal, através do decreto número 9.890, de 7 de julho de $1942^{7}$, tendo seu primeiro ano letivo somente em 1943. Os cursos ofertados foram em número de dois, um superior, que constou com a matricula de trinta e um alunos e um Normal, com seis alunas. A grade curricular, conforme indicava a legislação nacional, era a mesma da Escola Nacional de Educação Física (ALBIZÚ, 1944).

Inicialmente a instituição não possuía uma sede própria, funcionando de forma precária em diversos locais da cidade de Curitiba tais como: a Praça Ouvidor Pardinho, o Instituto Técnico de Agronomia, a Veterinária e Química do Paraná, o Clube Duque de Caxias, o curso de Inglês Inter-Americano, o Clube Circulo Militar, o Estádio Dorival de Brito e, por vezes, em mais de um lugar?.

Apesar de ser uma instituição privada, a Escola contava com uma pequena subvenção do governo estadual, mas, mesmo assim, tal contribuição não era suficiente para fazer a instituição funcionar de uma maneira eficaz. Na tentativa de amenizar as dificuldades, a instituição cobrava uma pequena mensalidade de seus/ suas alunos/as. Esses problemas de ordem financeira podem ser visualizados na correspondência expedida, no ano de 1944, pelo diretor-proprietário Albizú, ao então Interventor Federal Manoel Ribas:

Certo de que maior influxo ao seu desenvolvimento receberia a já florescente Escola de Educação Física do Paraná se fôr incorporada ao patrimônio e direção Estadoal, pois (...) contaria ainda com amplos recursos materiais que, estou convencido, permitiriam transformar - lá num dos mais bem aparelhados estabelecimentos de ensino dêste paiz e, estimulado pelo desejo de ver dotado o governo do Paraná de uma escola de educação física com todos os recursos indispensáveis, como a que fundei, a tão importante e imprescindível organização destinada a promover por todos os meios a cultura física da mocidade a par ao aperfeiçoamento intelectual, é que, com aprovação de meus colegas de congregação, tenho a satisfação de propôr a V. Excia.

7. É interessante salientar que a Escola de Educação Física e Desportos do Paraná, apesar de constar com alguns professores da Universidade do Paraná, instituição criada em I9|2, não possuía nenhuma ligação com a instituição que deu origem a Universidade Federal do Paraná. A sua agregação, ainda de forma parcial, ocorre somente em 1965 e se efetiva totalmente em 1977, quando passa a ser um Departamento dentro do Setor de Ciências Biológicas da Universidade Federal do Paraná.

8. O curso de inglês Inter-Americano também era de propriedade do Professor Albizú e era localizado no Prédio do edifício Garcez. Neste local funcionavam a Secretária da Escola e eram ministradas algumas aulas teóricas.

9. Estas informaç̧ões foram retiradas dos diversos relatórios apresentados a Divisão de Educação Física do Ministério da Educação e Saúde entre os anos de 1944 e 1960. 
a passagem para o Estado da atual Escola de Educação Física e Desportos do Paraná, sem qualquer indenização, apenas solicitando de V. Excia., como áto de justiça, a permanência nos seus postos os membros do corpo docente e administrativo (...) (ALBIZÚ, 1944, s.p).

○ corpo docente inicial, ao qual se referia o diretor era composto por sete professores e duas professoras. Estes jovens docentes estavam marcados por diversos discursos presentes no cenário nacional, pois eram médicos, militares e professores de Educação Física. Contudo, a organização não era tão simplista assim. Questões nacionais também se entrelaçavam com as existentes na cultura local. Afinal, suas origens étnicas e suas afinidades políticas se entrelaçavam com suas respectivas formações técnicas. Eram de origem imigrante e/ou da elite dirigente. Tinham proximidade com os grupos católicos, anticlericais, maçons, humanistas e muitas vezes até com mais de uma dessas opções. Além do proprietário Francisco Mateus Albizú, ${ }^{10}$ pertencia ao quadro docente os médicos Máximo Pinheiro de Lima"', Rozala Garzuze ${ }^{2}$, Jayme Drummond de Carvalho e Vivian Albizú de Carvalho $^{13}$. Completava o corpo docente os professores de Educação Física João

10. O professor Albizú era Bacharel em Pedagogia pela Faculdade de Filosofia, Ciências e Letras do Paraná, instituição na qual também se tornou professor na década de 1930. Foi também professor do Ginásio Paranaense e Inspetor de Educação Física do governo Estadual. Outro fato digno de nota era o seu pertencimento ao grupo católico. Ministrava as disciplinas de História da Educação Física e Organização da Educação Física e Metodologia da Educação Física.

1 I. Máximo Pinheiro de Lima era diplomado em Medicina pela Universidade do Paraná e fez o curso de Medicina Especializada em Educação Física pela Escola de Educação Física do Exército. Era também major da Força Policial do Estado do Paraná e professor da Faculdade de Filosofia, Ciências e Letras do Paraná, sendo uns dos introdutores na Antropologia no Estado do Paraná. Exerceu o cargo de vereador na cidade de Curitiba e foi o segundo diretor da Escola, no qual ministrava as disciplinas de Biometria/ Bioestatística e Fisioterapia.

12. O médico Rozala Garzuze era diplomado pela Faculdade de Medicina do Paraná, no qual se tornou professor de Patologia Geral. O professor era genro de Dario Vellozo, livre pensador ferrenho crítico do ideário católico. Rozala Garzuze após falecimento do sogro, em 1937, juntamente com Sebastião Paraná torna-se um dos principais expoentes do anticatolicismo na educação paranaense. O professor Garzuze além de médico era também escritor, filosofo e poeta. Na Escola de Educação Física e Desportos do Paraná trabalhou com a disciplina de Psicologia Aplicada.

13. Jayme Drummond de Carvalho era casado com a filha do fundador da escola, a professora Vivian Albizú de Carvalho. Ambos eram médicos formados pela Faculdade de Medicina do Paraná. Ela lecionou as disciplinas de Anatomia e Fisiologia Humana e ele as de Cinesiologia, Higiene Aplicada e Socorros e Urgências. O professor Jayme Drummond de Carvalho também tinha curso de Medicina Sanitária realizado no Instituto Manguinhos e de Saúde Pública no Instituto Oswaldo Cruz. Também era funcionário estadual e torna-se um dos médicos sanitaristas mais reconhecidos no Estado do Paraná a partir do final dos anos de 1940. 
Gualberto Gomes de Sál4 ${ }^{4}$ Halina Marcinowska ${ }^{15}$, Hamilton Saporski Dal' Lin ${ }^{16}$ e Neuzarth Franscisco Machado ${ }^{17}$.

Foi este jovem corpo docente, com algumas pequenas mudanças no decorrer dos anos seguintes, que constituiu o grupo inicial da Escola de Educação Física e Desportos do Paraná. Uma instituição criada para formar professores de Educação Física para o desenvolvimento e progresso de Curitiba e do Estado do Paraná. Um local criado com o projeto de educar os corpos dos indivíduos para uma vida urbana que se consolidava na capital paranaense.

\section{CONSIDERAÇÕES FINAIS}

Tais questões concernentes a Educação Física estão essencialmente articuladas com as reformas políticas e educacionais ocorridas no Brasil no início do século XX, pois foi por meio delas que se buscou educar o corpo social. Era um corpo marcado por inúmeras moléstias e doenças e que deveria sofrer a intervenção higienista, sob a gerência estatal. Baseados nessas normas médicas deveria se ajustar as condutas físicas e morais.

Assim estes novos dispositivos políticos circulantes em Curitiba se estruturaram como uma política de controle populacional mais ampla. $\bigcirc$ que estava em jogo era uma tentativa de intervenção sobre os corpos dos habitantes da capital paranaense em nome de uma vida urbana. Essa política de estado invadiu todos os setores da vida da população, normatizando-a de maneira a conformá-la aos fins sociais. A Educação Física e a Escola de Educação Física e Desportos do Paraná,

14. O major do Exército João Gualberto Gomes de Sá era filho do general João Gualberto, figura importante da sociedade paranaense. Tinha cursado o Colégio Militar do Rio de Janeiro, Escola Militar, Escola de Armas e Estado Maior e Escola de Educação Física do Exército, no qual também foi instrutor. Publicou artigos nos anos de 1930, sobre atletismo na Revista da Escola de Educação Física do Exército. Lecionou as disciplinas de Educação Física Geral e a de Ataque e Defesa. Porém, no final dos anos 40 briga com Albizú e retira-se do quadro de professores da instituição.

15. Halina Marcinowska era filha de poloneses. Cirurgiã Dentista diplomada pela Universidade do Paraná e em Ginástica pelo Instituto da Polônia (Varsóvia). Possuía ligação com importantes artistas, literatos e intelectuais paranaenses como Guido Viaro, o casal Emma e Ricardo Koch e Dalton Trevisan. Ministrou as disciplinas de Dança, Ginástica Rítmica e Ginástica Feminina.

16. Hamilton Saporski Dal'Lin filho de imigrantes italianos, diplomou-se em Educação Física pela Escola Superior de Educação Física do Estado de São Paulo e curso da Escola de Educação Física do Exército. Foi um importante difusor e defensor, tanto como atleta e dirigente, do atletismo no Paraná. Lecionou a disciplina de Desportos Terrestres Individuais.

17. Neuzarth Francisco Machado cursou a Escola de Educação Física do Exército. Possuía relações com o clube Duque de Caxias, de origem germânica. Trabalhou com as disciplinas de Desportos Terrestres Coletivos e Desportos Aquáticos. Porém, dois anos depois da criação da Escola se afasta do quadro de docentes sendo substituído pelo Prof. Germano Bayer. 
constituiu mais um dispositivo transformador de corpos em objeto de conhecimento e de possível intervenção. Não por isso, o lema da Educação Física na cidade de Curitiba consistia em educar o corpo para alcançar o objetivo de fazer da cidade a capital modelo do país.

\section{The context of foundation school of Physical Education and Sport of Paraná: educating bodys to an urban life}

ABSTRACT: The present article aims to analyze the socio-political context that favored the foundation of an institution that specifically intended to form professionals in the area of Physical Education: the School of Physical Education and Sports of Paraná. Established in Curitiba during the year of 1942, the School was fruit of an ample political scenery, in which the State, filled for eugenic/hygienic ideals, begins to worry more about the formal education. As a consequence, new physical and moral behaviors had been incorporated through the practices presented in the school's curriculum. Even with its singularities, the School of Physical Education and Sports of Paraná was an active part of this process.

KEYWORDS: School of Physical Education and Sports of Paraná; Physical Education; educational system; Curitiba.

\section{El contexto de la fundación de la Escuela de Educación Física y el Deporte de Paraná: educación de los cuerpos a una vida urbana}

RESUMEN: Este artículo examina el contexto socio-político que favoreció la fundación de una institución que se dirigía específicamente a la formación de profesionales en el área de Educación Física, Escuela de Educación Física y el Deporte de Paraná. Fundada en Curitiba en 1942, la Escuela fue el resultado de um amplio escenario político, en que el Estado, la higiene impregnado por los ideales / eugenesia, es estar más preocupados con la educación formal. En la reflexión, la conducta fisica y moral, se incorporaron nuevas por las prácticas actuales en los programas escolares. La Escuela de Educación Física y Deportes de Paraná, incluso con su singularidad, fue parte activa en este proceso.

PALABRAS CLAVES: Escuela de Educación Física y Deportes de Santa Catarina; Educación Física; Sistema Educativo; Curitiba.

\section{BIBLIOGRAFIA}

ALBIZÚ, F. M. Relatório apresentado ao Diretor da Divisão de Educação Física do Ministério da Educação e Saúde. Curitiba, mimeografado, 1944.

AVÉ-LALLEMANT, R. 1858, viagem pelo Paraná. Curitiba: Fundação Cultural, 1995.

BONI, M. I. M. de. O espetáculo visto do alto: vigilância e punição em Curitiba ( 890 - 1920). Curitiba: Aos Quatro Ventos, 1998. 
FUGMANN, W. Os alemães no Paraná. Ponta Grossa: Editora UEPG, 2008.

LINHALES, M. A escola, o esporte e a "energização do caráter": projetos culturais em circulação na Associação Brasileira de Educação (1925-1935). 266f. Tese (Doutorado em Educação) Programa de Pós-Graduação em Educação, Universidade Federal de Minas Gerais, Belo Horizonte, 2006.

MARTINEZ, C. P. Relatório do Inspector Geral de Ensino. Caio Pietro Martinez. Curityba, Typ. da Penitenciária do Estado, 1921.

MELO, V. A. de. Escola Nacional de Educação Física e Desportos: uma possível história. Dissertação 22 If. Dissertação (Mestrado em Educação Física). Faculdade de Educação Física, Universidade Estadual de Campinas, Campinas, 1996.

PEREIRA, M. R. de M. Semeando Iras Rumo ao Progresso. Curitiba: Editora da UFPR, 1996.

PINHEIRO DE LIMA, M. Jornal O Estado. Curitiba, 21 fev. 1937, p. I.

SOARES, C. L. Educación Física escolar en Brasil: breve historia de la constitución de una pedagogía higiénica. In: SCHARAGRODSKY, P. A. Gobernar es ejercitar: fragmentos históricos de la educación física en Iberoamérica. Buenos Aires: Prometeo Libros, 2008. p. 17-47.

TRINDADE, E. M. de C. Clotildes ou Marias: Mulheres de Curitiba na primeira república. Curitiba: Fundação Cultural, 1996.

TRINDADE, E. M. de C.; ANDREAZZA, M. L. Cultura e Educação no Paraná. Curitiba: SEED, 2001 .

Recebido: 21 mar. 2010

Aprovado: 02 fev. 2011

Endereço para correspondência

Marcelo Moraes e Silva Rua Martin Afonso, 226 - ap. 3

Bairro São Francisco

Curitiba-PR

CEP: $82530-000$

André Mendes Capraro Praça da Ucrânia, 44, apto I I |

Bairro Bigorrilho

Curitiba - PR

CEP: 80730-430 